\title{
Effect of Mental and Physical Practice on Clinical Skill Learning in Kinesiology
}

\author{
Melanie E. Perreault \\ The College at Brockport, State University of New York, mperreault@brockport.edu \\ Christopher Brown \\ University of Florida
}

Robert J. Doan

Charleston Southern University, rdoan@csuniv.edu

David R. Dolbow

William Carey University

Follow this and additional works at: https://nsuworks.nova.edu/ijahsp

Part of the Medicine and Health Sciences Commons

\section{Recommended Citation}

Perreault ME, Brown C, Doan RJ, Dolbow DR. Effect of Mental and Physical Practice on Clinical Skill Learning in Kinesiology. The Internet Journal of Allied Health Sciences and Practice. 2019 Jan 01;17(1), Article 8.

This Manuscript is brought to you for free and open access by the College of Health Care Sciences at NSUWorks. It has been accepted for inclusion in Internet Journal of Allied Health Sciences and Practice by an authorized editor of NSUWorks. For more information, please contact nsuworks@nova.edu. 


\title{
Effect of Mental and Physical Practice on Clinical Skill Learning in Kinesiology
}

\begin{abstract}
Purpose: The amount of information required for an allied health professional has increased dramatically. In-class practice time and large amounts of practice materials may be difficult for instructors to acquire. Mental practice is a method of practice that does not involve physical movement or materials. This study investigated the effect of mental practice, physical practice, and a combination of mental and physical practice on kinesiology students learning three manual muscle tests.
\end{abstract}

Method: Fifty-six students aged 18 to 26 years $(M=20.09, S D+1.58)$, pursuing a degree in kinesiology with an emphasis in either athletic training or kinesiotherapy participated in this study. Participants underwent two days of practice that included either mental practice, physical practice, or a combination of mental and physical practice for three Manual Muscle Tests (MMTs). Approximately 48 hours later, participants completed a post-test of the MMTs that was evaluated by two trained examiners. Participants also completed a survey related to demographics, difficulty of the MMTs, and intentions for using mental practice.

Results: The MMT post-test ANOVA revealed no significant learning differences between groups for all three Manual Muscle Tests. There were no significant differences in Manual Muscle Tests difficulty ratings between groups; however, there was a significant difference in participants' difficulty ratings across the Manual Muscle Tests. A majority of participants indicated they would use mental practice in the future.

Conclusions: The results indicated that kinesiology students seemed to learn equally well regardless of practice type. Utilization of mental practice in or outside of the classroom may be a strategy to supplement student learning in situations where class time and/or resources for physical skill practice may be more difficult to obtain.

\section{Author Bio(s)}

Melanie E. Perreault, PhD, is an Assistant Professor of Motor Behavior in the Department of Kinesiology, Sport Studies, and Physical Education at The College at Brockport, State University of New York.

Christopher Brown, PhD, LAT, ATC, CSCS, is a Clinical Assistant Professor of Athletic Training in the Department of Applied Physiology \& Kinesiology at the University of Florida.

Robert J. Doan, PhD, is Director of Graduate Program in the College of Education at Charleston Southern University.

David R. Dolbow, PT, DPT, PhD, RKT, is an Associate Professor of Physical Therapy in the School of Physical Therapy at William Carey University. 


\title{
IITAHSP \\ The Internet Joumnal of Allied Health Sciences and Practice \\ Dedicated to allied health professional practice and education \\ Vol. 17 No. 1 ISSN 1540-580X
}

\section{Effect of Mental and Physical Practice on Clinical Skill Learning in Kinesiology}

\author{
Melanie E. Perreault ${ }^{1}$ \\ Christopher Brown² \\ Robert J. Doan ${ }^{3}$ \\ David R. Dolbow 4
}

1. College at Brockport, SUNY

2. University of Florida

3. Charleston Southern University

4. William Carey University

United States

\begin{abstract}
Purpose: The amount of information required to educate an allied health professional has increased dramatically. In-class practice time and large amounts of practice materials may be difficult for instructors to acquire. Mental practice is a method of practice that does not involve physical movement or materials. This study investigated the effect of mental practice, physical practice, and a combination of mental and physical practice on kinesiology students learning three manual muscle tests (MMTs). Method: Fiftysix students aged 18 to 26 years $(M=20.09, S D \pm 1.58)$ pursuing a degree in kinesiology with an emphasis in either athletic training or kinesiotherapy participated in this study. Participants underwent two days of practice that included either mental practice, physical practice, or a combination of mental and physical practice for three Manual Muscle Tests. Approximately 48 hours later, participants completed a post-test of the MMTs that was evaluated by two trained examiners. Participants also completed a survey related to demographics, difficulty of the MMTs, and intentions for using mental practice. Results: The MMT post-test ANOVA revealed no significant learning differences between groups for all three Manual Muscle Tests. There were no significant differences in Manual Muscle Tests difficulty ratings between groups; however, there was a significant difference in participants' difficulty ratings across the Manual Muscle Tests. A majority of participants indicated they would use mental practice in the future. Conclusions: The results indicated that kinesiology students seemed to learn equally well regardless of practice type. Utilization of mental practice in or outside of the classroom may be a strategy to supplement student learning in situations where class time and/or resources for physical skill practice may be more difficult to obtain.
\end{abstract}

Key Words: Mental Practice; Skill Acquisition; Athletic Training Education, Kinesiology

(c) Internet Journal of Allied Health Sciences and Practice, 2019 


\section{INTRODUCTION}

Athletic training education is challenging for both students and faculty. Studies suggest that both students and faculty in athletic training programs experience a moderate to high level of emotional exhaustion. ${ }^{1,2}$ The amount of information students need to process and understand coupled with the limited time they have available to do so can be overwhelming for students. ${ }^{3}$ There are 229 educational competencies included within the National Athletic Trainers' Association $5^{\text {th }}$ edition of the Athletic Training Education Competencies. ${ }^{4}$ Many of these competencies involve some type of physical skill the student must master to become proficient. This challenge of proficiency is often made more difficult by limited practice opportunities for students within a class environment. In a recent study, athletic training students reported limited hands-on learning prior to clinical experiences as a common source of stress and frustration while completing their program. ${ }^{5}$ Since athletic training curricular requirements may leave little time for students to physically practice skills during class time, it is important to determine alternative practice methods that may aid clinical skill learning in and outside of the classroom.

Mental practice is an alternative practice approach researched extensively in the motor learning literature. It is defined as the cognitive rehearsal of physical skills in the absence of overt movement. ${ }^{6}$ Mental practice aids in skill acquisition by helping the learner create a mental blueprint (i.e., motor program) of the desired movement form. ${ }^{7}$ This mental blueprint allows the learner to understand the requirements of the skill and what needs to be done in order to successfully perform the movement. A major component of mental practice is imagery. Imagery involves replicating a past experience in one's mind using all relevant senses (e.g., kinesthetic, visual, etc.). For example, a basketball player imaging the execution of a free throw might see the rim of the basket (visual), feel his wrist snap forward during the release (kinesthetic), and hear the swishing sound of the ball entering the net (auditory). Likewise, an athletic trainer imaging the treatment of an on-field injury might see the athlete clutching her knee (visual), feel the way the body responds to a physical examination (kinesthetic), and hear the verbal reaction from the athlete during the exam (auditory).

Imagery content can vary substantially based on the individual and situation; however, images usually falls within one or more of the five major categories8: 1) cognitive specific (CS; skills rehearsal); 2) cognitive general (CG; strategy rehearsal); 3) motivational specific (MS; goal setting); 4) motivational general-arousal (MG-A; arousal regulation); and 5) motivational general-mastery (MG$\mathrm{M}$; confidence building). Although this model was originally developed for sport-based imagery, it has been replicated in athletic training. ${ }^{9}$ In an instructional setting, athletic training students may benefit most from mental practice that uses imagery focused on skills rehearsal (i.e., CS). For example, a student learning to tape an ankle could image her/himself performing the skill correctly using any relevant senses (e.g., seeing the position of the tape, feeling the movements of the hands).

The Commission on Accreditation of Athletic Training Education requires accredited programs to provide instruction on Psychosocial Intervention and Referral as part of the Athletic Training Educational Competencies. ${ }^{4}$ One of these competencies (PS-7) focuses on the use of psychological techniques (e.g., goal setting, imagery, positive self-talk) to motivate or help an injured athlete return to play. Since this competency focuses exclusively on the rehabilitation setting, athletic training students may not see the utility of using these psychological techniques, such as mental practice, in other contexts (e.g., classroom). Additionally, athletic trainers have ranked mental practice and imagery as less important and less effective in comparison to others psychological techniques. ${ }^{10-12}$ However, mental practice has consistently shown to facilitate motor learning especially for skills with a large cognitive component, which is characteristic of most clinical skills. ${ }^{13,14}$ Moreover, research with medical students suggests that a combination of mental and physical practice is superior to physical practice alone for learning surgical skills. ${ }^{15}$

Although teachers and students alike might intuitively favor physical practice over mental practice and imagery, practical limits on instructional time and resources may not allow for adequate physical practice opportunities to facilitate student learning; thus, an alternative practice approach may need to be considered. What remains unclear is whether the learning benefits of mental practice or a combination of mental and physical practice can be replicated with individuals learning clinical skills in an athletic training education setting. Thus, the primary purpose of our study was to examine the effect of mental practice, physical practice, and a combination of mental and physical practice on students learning three clinical skills: manual muscle tests of the 1) middle deltoid, 2) middle trapezius, and 3) supraspinatus. Based on the previous literature, we hypothesized that a physical practice and combination group would outperform a mental practice group on post-test measures of each MMT. Since student buy-in is important when implementing new pedagogical strategies, a secondary purpose of the study was to examine student intention to use mental practice while completing their degree program

\section{METHODS}

\section{Participants}

Fifty-six students aged 18 to 26 years $(M=20.09, S D=1.58)$, pursuing a degree in kinesiology with an emphasis in either athletic 
training (AT; $n=16)$ or kinesiotherapy (KT; $n=40)$, from a large southeastern university volunteered for this study. Educators from both programs participated in participant recruitment through email and verbal solicitations during a class session. Participants were included if they had declared AT or KT as a major but had not been formally admitted to either program and had no prior knowledge of any of the skills utilized in the study. Each participant was randomly assigned to one of three gender- and majorstratified groups to help prevent any potential confounding variables: 1$)$ mental practice $(n=17) ; 2)$ physical practice $(n=19)$; or 3 ) combined mental and physical practice $(n=20)$. Group sizes were unequal due to participant attrition.

\section{Tasks}

Manual muscle tests (MMTs) were selected as the tasks because they are clinical skills that students in the AT and KT program need to learn, and these tasks potentially vary in level of difficulty. The three muscles selected for testing were the 1) middle deltoid, 2) middle trapezius, and 3) supraspinatus. Each MMT was taught according to procedures from Kendal et al, and can be seen in Figure $1 .{ }^{16}$

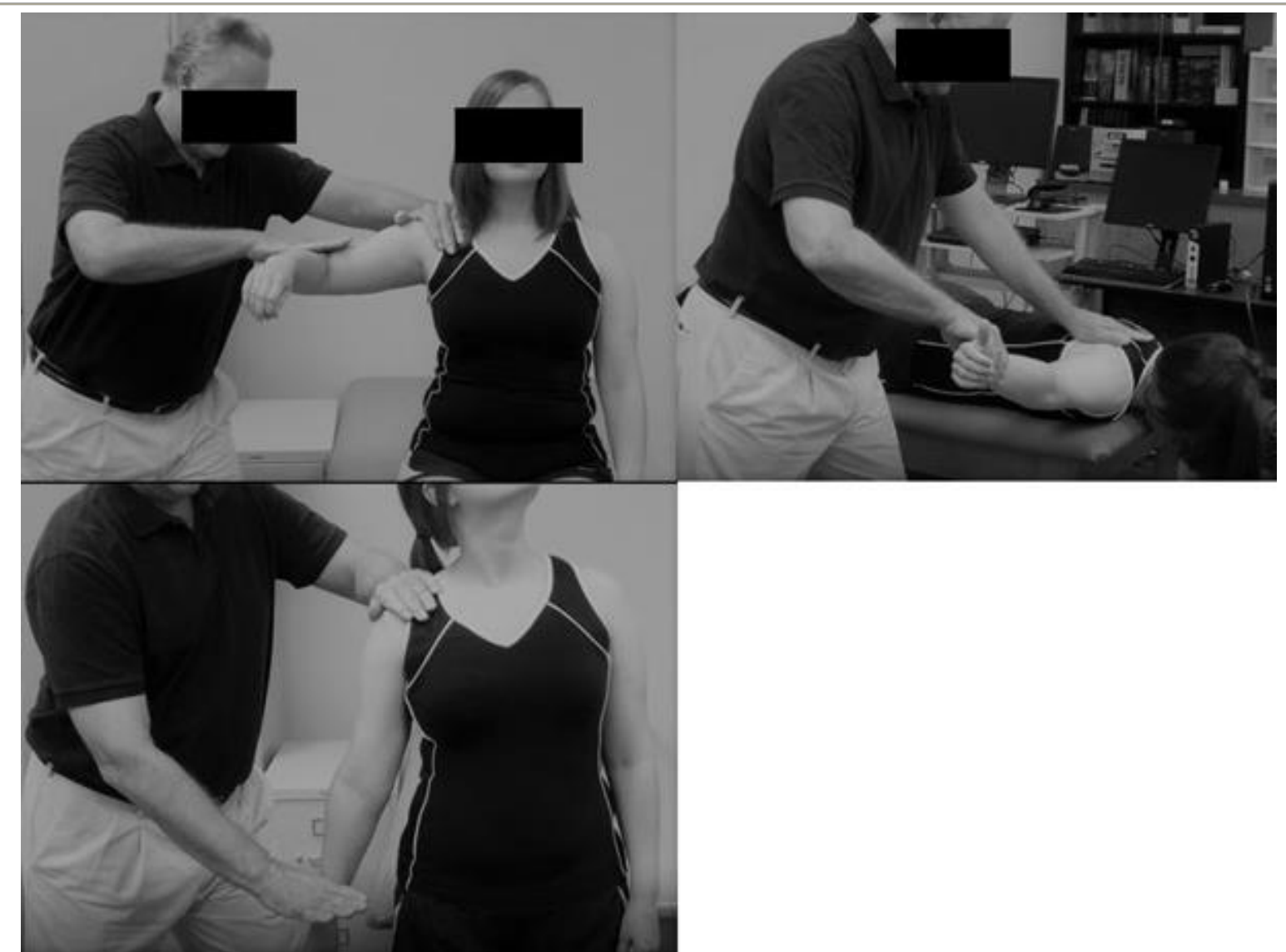

Figure 1: Manual Muscle Tests. Clockwise from top left to right - middle deltoid, middle trapezius, supraspinatus

\section{Procedure}

Institutional Review Board approval was obtained prior to the start of the study. All participants read and signed an informed consent document before inclusion in the study. Extra credit was offered in all classes for participation in the study. Pre-tests were not administered because participants had no prior knowledge of the MMTs being taught. ${ }^{17}$

Practice Day 1. At the start of the first practice day, all participants were told they would be learning three MMTs over two practice days and would be physically tested at the end of the week. Participants in the mental practice group were also given the following definition and example of mental practice with a CS (i.e., skills rehearsal) focus in order to ensure they understood what was expected of them: "Mental practice refers to the symbolic rehearsal of a physical activity in the absence of any gross muscular movements." ${ }^{\prime 6}$ For example, a basketball player may mentally image execution of a correct free throw technique prior to stepping up to the free throw line. A researcher was present to clarify further, if needed. 
For each group, the MMTs were taught using three instructional videos (one for each MMT) embedded in a PowerPoint presentation. Each video contained a demonstration of the MMT with voiced-over and closed-captioned instructions. Participants viewed each video three times. Immediately following each viewing, participants were given 30 seconds to practice the corresponding MMT (either physically or mentally) they had just seen one time. We chose the amount of practice time based on pilot testing to ensure that all participants had adequate time to complete their practice attempt. We repeated this process for the remaining two MMTs until all three had each been watched and practiced three times. The combination group attended the physical practice session on Day 1 and attended the mental practice session on Day 2. We chose the order to mimic typical classroom conditions in which instruction and physical practice is normally given when introducing a new skill.

Practice Day 2. The second practice day took place approximately 48 hours following the first practice day. First, all participants were reminded that they would be physically tested on the MMTs at the end of the week. Participants in the mental practice and combination groups were also provided with the definition and example of mental practice with a CS focus from the first practice day in order to ensure the participants in the combination group understood what was expected of them. A researcher was present to clarify further, if needed. Next, participants viewed each MMT video one time to refresh their memory. Immediately following each video, participants were given 90 seconds to practice the corresponding MMT (either physically or mentally) they had just seen three times. We chose the amount of time to correspond with the total amount of time participants practiced during the first practice day. We repeated this process for the remaining MMTs until all three tasks had each been watched and practiced three times.

Post-Test. Post-test measures were taken approximately 48 hours following participants' last skill instruction. Two trained examiners (program faculty), blinded to practice group, administered and scored each examination concurrently using a checklist (see Table 1). A standardized model was used during testing in order to decrease error. One examiner read a set of instructions to the participant and started a timer. The participant had 2 minutes to perform each skill. The examiners scored the first attempt. After 2 minutes had elapsed or an attempt was scored the next set of instructions was read to the participant. We repeated this protocol for all three MMTs.

Table 1: Examiner Checklist

\begin{tabular}{|c|c|}
\hline Muscle & Instructions \\
\hline Middle Deltoid MMT & $\begin{array}{ll} & \text { Examiner instructs patient to sit } \\
\square & \text { Patient's shoulder is placed in } 90 \text { degrees of abduction } \\
\square & \text { Patient's elbow is flexed to } 90 \text { degrees } \\
\square & \text { Examiner's hand stabilizes the shoulder joint } \\
\square & \text { Examiner's other hand is placed on the superior portion of the elbow } \\
\square \quad \text { Pressure is applied into shoulder adduction } \\
\square \quad \text { Pressure is applied for } 3-5 \text { seconds }\end{array}$ \\
\hline Middle Trapezius MMT & $\begin{array}{l}\quad \text { Instructs model to lie prone at the edge of the table } \\
\square \quad \text { Shoulder is placed in } 90 \text { degrees abduction } \\
\square \quad \text { Shoulder is laterally rotated so that thumb is pointing up } \\
\square \quad \text { Scapula is retracted by bringing the arm upwards } \\
\square \quad \text { Places a stabilization hand on same side scapular area } \\
\square \quad \text { Applies pressure against the superior distal arm } \\
\square \quad \text { Pressure is applied into Horizontal Adduction } \\
\square \quad \text { Pressure is applied for 3-5 seconds }\end{array}$ \\
\hline Supraspinatus MMT & $\begin{array}{l}\square \quad \text { Examiner instructs Patient to stand } \\
\square \quad \text { Examiner passively extend and laterally flex Patient's head to same side } \\
\square \quad \text { Examiner turns face to opposite side (or instructs Patient) } \\
\square \quad \text { Examiner's stabilizing hand on shoulder that head is flexed towards } \\
\square \quad \text { Patient is instructed try to bring arm away from body } \\
\square \quad \text { Pressure is applied on distal forearm into Adduction to resist Patient bringing arm away } \\
\text { from body } \\
\square \quad \text { Pressure is applied for 3-5 seconds }\end{array}$ \\
\hline
\end{tabular}


Following the post-test, participants completed a brief written survey containing questions related to demographics (see Participants), difficulty of the MMTs, and their intentions toward using mental practice while completing their degree in AT or KT. Participants rated the difficulty of each MMT using a 6-point Likert scale from 0 (extremely easy) to 5 (extremely difficult). Participants indicated their intentions toward using mental practice by responding to the following question: "Do you see yourself using mental practice while completing your degree in athletic training or kinesiotherapy?" Depending on the participants' responses, they were asked to respond to one of two follow up questions, "If YES, how would you use mental practice?" or "If NO, why would you not use mental practice?". The same definition and example of mental practice provided to the mental practice group during practice was provided prior to the question to ensure that all participants understood the meaning of the term, especially those in the physical practice group.

\section{Data Analysis}

A p-value of 0.05 was used to determine significance. IBM SPSS software version 24 was used for statistical analysis.

MMT Post-test Scores. Adequate inter-rater reliability was obtained across the two examiners ( $\mathrm{k}=.76-.87) .{ }^{18}$ Participants' scores were then averaged across the two examiners and converted to a percentage. This represented the total amount of correct skill components performed. A one-way ANOVA was used to calculate the effect of condition on MMT posttest scores.

MMT Difficulty. A Kruskal-Wallis test was conducted comparing the difficulty rating of each MMT with condition. A Friedman ANOVA was then conducted comparing participants' difficulty rating across all three MMTs. Post hoc tests were conducted, if needed.

Mental Practice Intentions. A Kruskal-Wallis test was conducted comparing responses to the mental practice question with condition. Responses to the follow-up questions were evaluated for content and categorized based on common themes: skill practice, clinical planning, mental skills, learning preference, and irrelevant. Two researchers then independently coded each of the responses and adequate inter-rater reliability was obtained $(k=.60) .{ }^{18}$

\section{RESULTS}

\section{MMT Post-test Scores}

The ANOVA revealed no significant learning differences between groups for all three manual muscle tests $(p>05)$. Even though there were no significant differences, there seemed to be a trend for better performance and less variability in the mental practice group (see Figure 2).

\section{MMT Difficulty}

The Kruskal-Wallis test revealed no significant differences in difficulty ratings between groups $(p>.05)$. However, the Friedman ANOVA did reveal a significant difference in participants' difficulty ratings across the MMTs, $X^{2}(2)=13.35, p=.001$. Wilcoxon Signed-Ranks tests indicated that the middle deltoid MMT was rated significantly less difficult than the middle trapezius $(Z=-$ $3.03, p=.002)$ and supraspinatus MMTs $(Z=-2.12, p=.034)$, which did not differ significantly from one another $(Z=-.49, p=$ .625).

\section{Mental Practice Intentions}

When responding to the mental practice intention question, $77 \%$ of all participants responded affirmatively. Interestingly, when responses were separated by group, the physical practice group had the highest percentage of affirmative responses (84\%) followed by the mental practice (82\%) and combination (65\%) groups; however, the Kruskal-Wallis test revealed no significant differences between groups $(p>.05)$. 


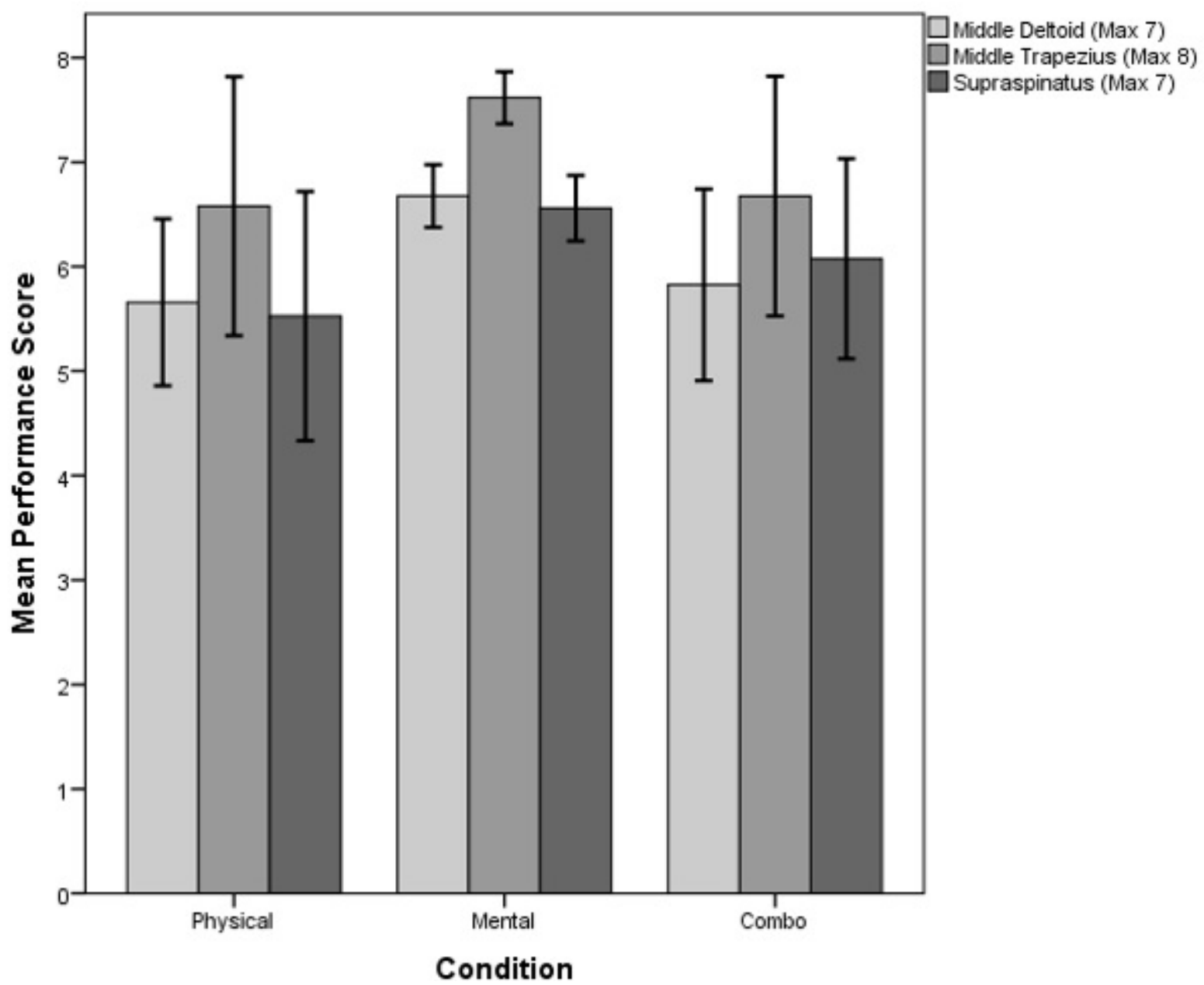

Figure 2. Mean performance per condition for each MMT. Error bar represents $95 \%$ confidence interval.

Responses to the follow-up questions were similar across groups; however, some clear trends were evident across all participants (see Figure 3). For those who expressed that they would use mental practice, the majority $(81 \%)$ indicated they would use it for skill practice (i.e., to practice/rehearse clinical skills). Examples include the following: "I would need to mentally trace my steps in things I'm doing. Sometimes I might not have someone to practice on" (physical); "To teach myself the exercises in free time" (mental); "I can picture myself doing the tasks, and the more I picture and review it, the easier it will be" (combination). All participants who expressed they would not use mental practice indicated it was due to a preference for some form of kinesthetic/hands-on learning. Examples include the following: "Because I learn better through actions rather than mental" (physical); "I think it is easier and also more helpful to physically perform the action" (mental); "I'm a hands-on learner. I would rather do physical activity" (combination). 


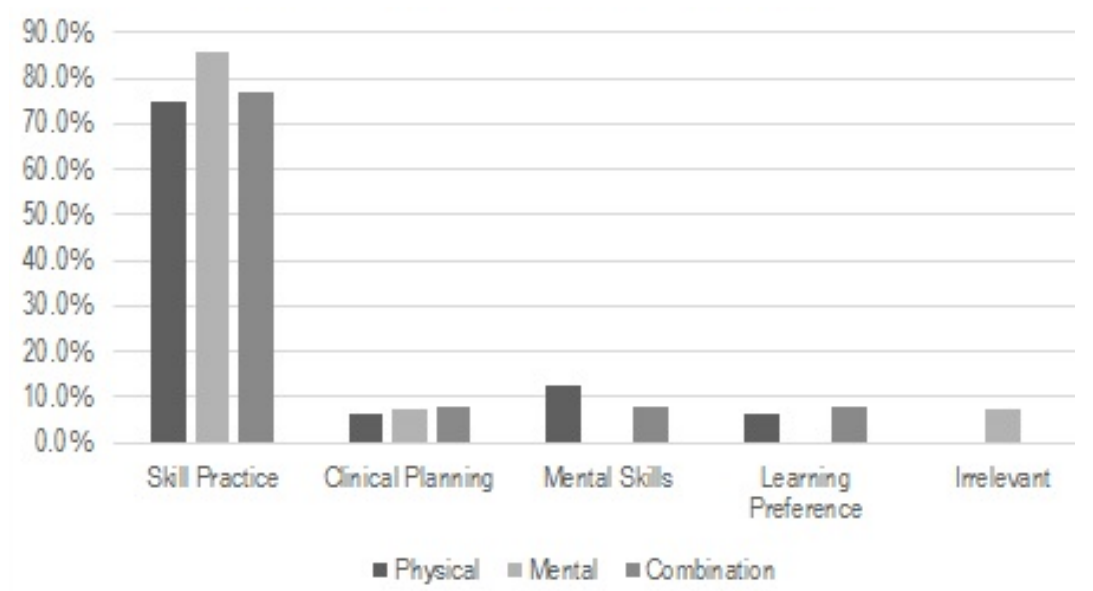

Figure 3. Self-reported reasons why participants would use mental practice

\section{DISCUSSION}

Given the amount of clinical skills that are taught in allied health professional curriculums, it is increasingly important for educators to find innovative and potentially time-saving techniques for teaching clinical skills. Thus, the purpose of this study was to determine the effects of mental and physical practice on kinesiology students' clinical skill learning. Our results indicate all kinesiology students learned the MMTs equally well regardless of the type of practice used during the two practice days or the perceived differences in MMT difficulty. This finding deviates from previous research on sport-related and surgical skills in that individuals using only mental practice do not tend to learn as effectively as those using physical practice or a combination of both. ${ }^{13,15}$ However, it is noteworthy that the majority of participants in our study indicated that they would use mental practice while completing their degree despite some participants not having used it during training. In fact, the physical practice group had the highest percentage of participants indicating that would use mental practice while completing their degree. The most commonly cited reason across groups was to practice or rehearse clinical skills, which coincides with the CS function of imagery. Although this is not surprising given that the focus of our study was on clinical skill learning, practicing ATs have also reported using CS imagery second only to MG-M imagery. ${ }^{9}$ Since our participants are predominantly exposed to traditional pedagogies (e.g., lecture) in their respective programs, they might assume they will have limited opportunities for physical practice in or outside of the classroom; thus, there is a need for an alternative form of practice. Those in our study that indicated they would not use mental practice cited a preference for hands-on learning; however, this is not unusual given AT students' perception of hands-on learning as an effective educational practice. ${ }^{19}$

A potential confounding variable may account for our results. Observational learning, or modeling, is an effective tool for learning a variety of behaviors. Bandura suggests that this is a result of the transmission of visual information into a store representation of the behavior that can be recalled for later use by the learner when attempting the same behavior. ${ }^{20}$ Since mental practice is also thought to aid in the development of a stored representation of a movement, they are often thought of as similar processes. However, one major distinction is that observational learning originates from an external source, such as a live model or video demonstration, whereas mental practice occurs internally. When examined as separate processes, research suggests that modeling alone or in combination with imagery contributes to more effective performance and learning of motor skills than the use of imagery alone. ${ }^{21,22}$ Thus, the performance of each group on the post-test in our study may have more to do with the repeated exposure to the video demonstrations than with the type of practice used during training. However, without the inclusion of a modeling only condition, we cannot be sure this was the case.

At first, the potential confounding influence of the video demonstrations seems problematic to our study; however, it may provide some evidence to support the use of alternative pedagogies in AT education. Specifically, the flipped classroom, which has been gaining attention in higher education over the past several years, may lend itself well to teaching clinical skills. It consists of students spending time out of class engaging in content in a format that might normally take place during class (e.g., pre-recorded video lectures) and frees class time for more interactive and hands-on activities. ${ }^{23}$ Using this approach, students could have multiple opportunities to engage in observational learning (i.e., view demonstrations) of the skills before class as well as more time to participate in physical practice during class. Since AT students have cited both observational learning and hands-on learning as valuable for their professional education, student buy-in to the flipped classroom may not be as challenging as some other types of alternative pedagogies. ${ }^{19}$ Moreover, research indicates that the flipped classroom increased student engagement in an AT 
course and was equally or more effective than traditional instruction for student learning in nursing courses, a related allied health field. ${ }^{24,25}$ However, continued research specific to AT is needed.

\section{Limitations}

The findings of the current study are limited to the MMTs performed by the kinesiology students and cannot be generalized to all clinical skills; thus, future research is needed to replicate the findings. This study did not include a control condition because the skills were completely novel and the likelihood of history as an internal threat to validity was minimal. However, our study would have benefitted from a modeling only condition in order to determine how observational learning might act as a mediating variable. This was unanticipated when we conceptualized the original study design; however, its inclusion is recommended in future research. Additionally, we could not control for participants practicing outside of the study, whether physically or mentally; thus, we cannot be sure if the amount of practice outside of training influenced the results. Finally, the extra credit participants received for participating in the study may have influenced their performance. For example, they may have tried harder to learn the skills than in a normal classroom setting or they may have felt additional pressure to perform well.

\section{CONCLUSIONS}

This study compared mental and physical practice and its effect on clinical skill learning. The results indicated that kinesiology students seemed to learn equally well regardless of practice type. This finding must be interpreted with caution due to the potential influence of observational learning. Even so, utilization of mental practice in or outside of the classroom may be a strategy to supplement student learning in situations where class time and/or resources for physical skill practice may be more difficult to obtain. Moreover, the majority of students involved in the study indicated they would use mental practice at some point while completing their degree. Thus, student resistance to its use as a classroom strategy may be minimal.

\section{REFERENCES}

1. Riter TS, Kaiser DA, Hopkins JT, Pennington TR, Chamberlain R, et al. Presence of burnout in undergraduate athletic training students at one western US university. Athl Train Ed J. 2008;2:57-66.

2. Walter JM, VanLunen B, Walker SE, Ismaeli ZC, Onate JA. An assessment of burnout in undergraduate athletic training education program directors. J Athl Train. 2009;44(2):190-6. [PMID: 19295965]

3. Mazerolle SM, Pagnotta KD. Student perspectives on burnout. Athl Train Ed J. 2011;6(2):60-8.

4. $\quad$ NATA. Athletic Training Educational Competencies 5th Edition, 2011.

5. Mauzy J, Bowman T, Mazerolle S, Fister C. Factors of stress, burnout, and frustrations experienced by athletic training students. Internet J Allied Health Sci Pract. 2015;13(2):1-14.

6. $\quad$ Richardson A. Mental practice: A review and discussion part 1. Res Quart. 1967;38:95-107.

7. Sackett RS. The influence of symbolic rehearsal upon the retention of a maze habit. J Gen Psych. 1934;10(2):376-98.

8. Martin K, Moritz S, Hall C. Imagery use in sport: A literature review and applied model. Sport Psychol. 1999;13:245-68.

9. Monsma EV, Trier C, Perreault ME, Seiler BD, Torres-McGehee TM, et al. The cognitive and motivational functions of imagery among athletic trainers. J Imagery Res Sport Phys Activ. 2011;6(1):Article 5.

10. Larson G, Starkey C, Zaichkowsky L. Psychological aspects of athletic injuries as perceived by athletic trainers. Sport Psychol. 1996;10(1):37-47.

11. Weise D, Weiss M, Yukelson D. Sport psychology in the training room: a survey of athletic trainers. Sport Psychol. 1991;5(1):15-24.

12. Hamson-Utley J, Martin S, Walters J. Athletic Trainers' and Physical Therapists' perceptions of the effectiveness of psychological skills within sport injury rehabilitation programs. J Athl Train. 2008;43(3):258-64.[PMID: 18523575]

13. Feltz D, Landers D, Becker B. A Revised Meta-analysis of the Mental Practice Literature on Motor Skill Learning. Washington, DC: National Academy Press; 1988.

14. Driskell J, Copper C, Moran A. Does mental practice enhance performance? J Appl Psych. 1994;79(4):481-92.

15. Anton NE, Bean EA, Hammonds SC, Stefanidis D. Application of mental skills training in surgery: A review of its effectiveness and proposed next steps. J Laparoendosc Adv Surg Tech A. 2017;27(5):459-68. [PMID: 28225325]

16. Kendall FP, Kendall FP. Muscles: Testing and Function with Posture and Pain, 5e. Baltimore, MD: Lippincott Williams \& Wilkins; 2005.

17. Bloomfield J, Roberts J, While A. The effect of computer-assisted learning versus conventional teaching methods on the acquisition and retention of handwashing theory and skills in pre-qualification nursing students: a randomized controlled trial. Int J Nurs Stud. 2010;47(3):287-94. [PMID: 19762016]

18. Landis JR, Kock GG. The measurement of observer agreement for catagorical data. Biometrics. 1977;33:15974.[PMID: 843571] 
19. Mensch J, Ennis C. Pedagogic strategies perceived to enhance student learning in athletic training education. J Athl Train. 2002;37(4 Supplement):S199-207.[PMID: \#12937545]

20. Bandura A. Social Foundations of Thought and Action : A Social Cognitive Theory. Englewood Cliffs, NJ: Prentice-Hall; 1986.

21. SooHoo S, Takemoto K, McCullagh P. A comparison of modeling and imagery on the performance of a motor skill. $J$ Sport Beh. 2004;27(4):349-66.

22. Ram N, Riggs S, Skaling S, Landers D, McCullagh P. A comparison of modelling and imagery in the acquisition and retention of motor skills. J Sports Sci. 2007;25(5):587-97.[PMID: 17365544]

23. Berrett D. How 'flipping' the classroom can improve the traditional lecture. Chron High Educ. 2012;12:1-14.

24. Thompson G, Ayers S. Measuring student engagement in a flipped athletic training classroom. Athl Train Ed J. 2015;10(4):315-22.

25. Betihavas V, Bridgman H, Kornhaber R, Cross M. The evidence for "flipping out": A systematic review of the flipped classroom in nursing education. Nurse Educ Today. 2016;38:15-21.[PMID: 26804940] 